\title{
Birds in the Backyard
}

Shikra (Accipiter badius)
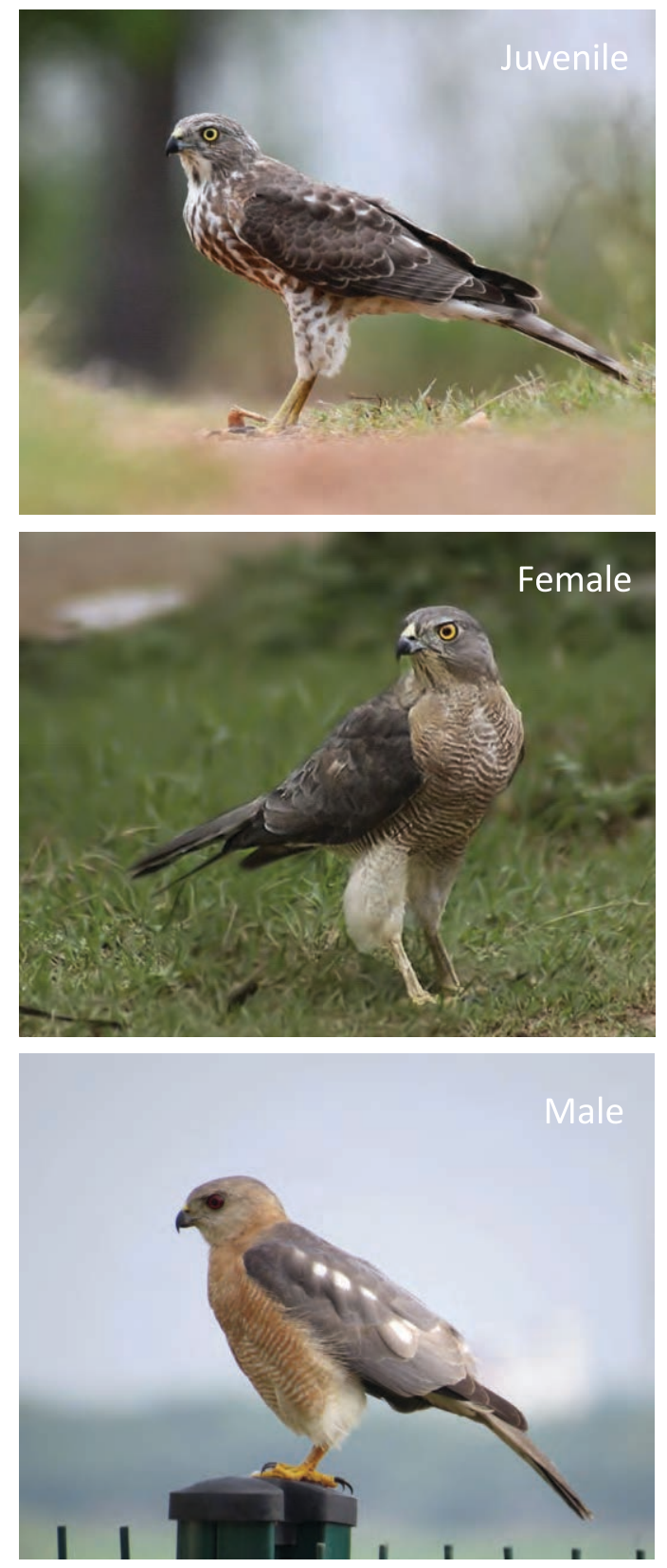

The Shikra is a small hawk, resident across south and southeast Asia, as well as across large parts of Africa. Adults have brown-grey (more bluish-grey in males and brown in females) upper parts, and are whitish barred with rufous below. Males, who are slightly smaller than females, have lighter barring on the underside, and juveniles have heavy, dark brown streaks. The iris of the eye is yellow in females and reddish in males. A thin, dark stripe runs down the throat. The tail is slightly long and has dark bands. The shikra is seen in wooded, agricultural, and urban areas, singly or in pairs, and has a loud, sharp, two-note call, which drongos sometimes imitate. The Common Hawk Cuckoo (Hierococcyx varius; Papeeha) resembles the shikra; cuckoo - hawk similarity is thought to help brood parasites by scaring away host birds.

The shikra(namederived from shikari, hunter) hunts various birds, rodents, squirrels, and reptiles, and also feeds on emerging winged termites. It has a cultural association in the Indian subcontinent, being used by falconers in the past, and alluded to in poetry.

\section{By: T.N.C. Vidya}

Photo credits (Top down): Syed Abdul Khuddus (Mysuru), Ragoo Rao(Mysuru), Pramathanath Sastry(Chennai Mathematical Institute) 